\title{
FORMAÇÃO DOCENTE NUM CONTEXTO DE INCLUSÃO ESCOLAR: "ALTERIDADE: EU NO LUGAR DO OUTRO"
}

\section{EDUCATIONAL TRAINING IN A CONTEXT OF SCHOOL INCLUSION: "ALTERITY: I AM IN THE PLACE OF OTHERS"}

\author{
TEIXEIRA, Adriana Martins Modesto ${ }^{1}$ \\ VIANNA, Marcia Marin²
}

\begin{abstract}
RESUMO
O presente artigo tem como objetivo relatar uma experiência através de uma proposta de intervenção pedagógica realizada em uma escola de Educação Básica, privada, do município de Itu, interior do Estado de São Paulo. A intervenção se constituiu da oferta e realização de uma oficina pedagógica para formação docente continuada, que teve por título: "Alteridade: eu no lugar do outro", foi uma proposta de sensibilização para o corpo docente da escola, de modo a trazer o conceito de alteridade como uma vivência, para que os profissionais pudessem refletir sobre o que é uma pessoa com deficiência. Além disso, a ideia era promover a reflexão sobre como poderiam contribuir, de fato, para a inclusão de alunos com deficiência ou qualquer outra peculiaridade no seu processo de aprendizagem. Essa oficina pedagógica teve como propósito incentivar e sensibilizar os professores sobre a importância da inclusão nas instituições de ensino comum; foi dinamizada por meio de atividades prático-reflexivas que visaram à sensibilização e o despertar de um olhar diferenciado dos educadores a todos os alunos com necessidades educacionais especiais. Como resultado observou-se a inquietação do grupo de professores e um novo olhar sobre as temáticas selecionadas. Entretanto, entendemos também que não se tratou de um rompimento definitivo com algumas mentalidades que não estão de acordo com os princípios inclusivos. A oficina pode ser compreendida como geradora de reflexões e incômodos que podem despertar interesse e busca por novas perspectivas para um novo pensar e agir na docência.
\end{abstract}

PalAVRAS-ChaVE: educação inclusiva; formação docente; oficina pedagógica; alteridade.

\begin{abstract}
This article aims to report an experience through a proposal of pedagogical intervention carried out in a private school in the city of Itu, in the state of São Paulo. This intervention consisted in the offer and realization of a pedagogical workshop for continued teacher training, entitled "Alterity: I in the place of the other". It was a proposal of sensitization for the faculty of the school, in order to bring the concept of alterity as an experience, so that professionals could think about what a person with a disability actually is. In addition, the idea was to promote reflection on how they could contribute for the inclusion of students
\end{abstract}

\footnotetext{
1 Universidade Federal de Juiz de Fora (UFJF). Juiz de Fora, MG, Brasil. e-mail: adriana.modesto@hotmail.com

${ }^{2}$ Universidade Federal de Juiz de Fora (UFJF). Juiz de Fora, MG, Brasil. Colégio Pedro II (CPII). Rio de Janeiro, RJ, Brasil. e-mail: marinvianna2014@gmail.com
} 
DOI: $10.12957 /$ e-mosaicos.2020.46091

with disabilities or any other peculiarity in their learning process. This pedagogical workshop had the purpose of encouraging and sensitizing teachers about the importance of inclusion education in regular institutions; it was stimulated through practical and reflexive activities that aimed at raising awareness and awakening a differentiated view of educators to all students with special educational needs. As a result, the teacher group's concern and a new look at the selected themes were observed. However, we also understand that it was not a definitive break with some thoughts that do not conform to inclusive principles. The workshop can be understood as creating reflections and annoyances that can cause interest and search for new perspectives for a new thinking and acting in teaching.

KEYWORDS: inclusive education; educational training; pedagogical workshop; alterity.

\section{INTRODUÇÃO}

A questão da formação de professores tem sido alvo de inúmeras preocupações e pesquisas atreladas às questões da qualidade do ensino no Brasil. No contexto atual da política educacional brasileira, em que esforços têm sido concretizados no sentido de garantir uma educação de qualidade pautada nos referenciais para uma sociedade inclusiva, apresentam-se novas práticas pedagógicas, oriundas da necessidade de modificação das estruturas educacionais, como forma de garantir a efetivação dos princípios estabelecidos para a construção de uma sociedade inclusiva e plural.

Nessa perspectiva, pensar sobre formação docente para a educação inclusiva torna-se fundamental para a compreensão e desvelamento dos modelos educacionais vigentes e das práticas pedagógicas que sustentam tais modelos.

Segundo Mantoan (2003, p.43):

Formar o professor na perspectiva da educação inclusiva implica ressignificar o seu papel, o da escola, o da educação e o das práticas pedagógicas usuais do contexto excludente do nosso ensino, em todos os níveis. [...] a inclusão escolar não cabe em uma concepção tradicional de educação. A formação do professor inclusivo requer o redesenho das propostas de profissionalização existentes e uma formação continuada que também muda.

Um dos grandes desafios para a concretização da cultura da inclusão nos sistemas de ensino está na formação inicial e continuada dos professores que muitas vezes se sentem despreparados para atuarem de acordo com a diversidade presente na escola.

Se o processo de inclusão não vier acompanhado de suportes pedagógicos adequados para o aluno e o professor, se a Educação Especial continuar sendo um sistema paralelo de atendimento e os professores continuarem atuando isoladamente, não alcançaremos a 
DOI: $10.12957 / \mathrm{e}-\mathrm{mosaicos} .2020 .46091$

utopia da inclusão escolar: meninos e meninas, com ou sem deficiência aprendendo e convivendo juntos na escola. Ademais, se a formação de professores não for pensada e adequada nos contextos educacionais que vêm se delineando na atualidade continuaremos enfrentando grandes dificuldades para construir efetivamente uma escola democrática e inclusiva (ANTUNES; GLAT, 2011, p.198).

Nesta perspectiva, a formação de professores, tanto inicial como continuada, precisa ser revista para que possamos mudar o cenário educacional brasileiro, para que este se adeque aos requisitos da Educação Inclusiva. Inúmeros estudos vêm mostrando que os professores, embora sensibilizados com o conceito de / a ideia de inclusão escolar, se sentem (e, de fato o são) pouco preparados para atender alunos com deficiência ou outros transtornos (PLESTCH, 2009; ANTUNES \& GLAT, 2011; entre outros).

Diante de tais preocupações, o presente trabalho aborda uma proposta de intervenção pedagógica para 25 docentes do segmento do Ensino Infantil, Fundamental I e II e também do Ensino Médio de uma escola particular no município de Itu, interior do Estado de São Paulo.

Essa oficina pedagógica teve como propósito incentivar e sensibilizar os professores sobre a importância da inclusão nas instituições de ensino comum, e foi dinamizada por meio de atividades prático-reflexivas que visaram à sensibilização e o despertar de um olhar diferenciado dos educadores a todos os alunos com necessidades educacionais especiais.

A inclusão desses alunos em instituições comuns de ensino é assegurada pela legislação brasileira. A Resolução $n^{\circ}$ 2/2001 (BRASIL, 2001) instituiu as Diretrizes Nacionais para a Educação Especial na Educação Básica e promoveu um avanço na concepção sobre a atenção aos Planos Nacionais de Educação (PNE) na rede de ensino nacional, conforme disposto em seu art. 2:

Os sistemas de ensino devem matricular todos os alunos, cabendo às escolas organizar-se para 0 atendimento aos educandos com necessidades educacionais especiais, assegurando as condições necessárias para uma educação de qualidade para todos (BRASIL, 2001).

No que tange à Lei de Diretrizes e Bases da Educação Nacional, em seu Capítulo V da Educação Especial, temos a definição da Educação Especial contida no art. 58:

Art. 58. Entende-se por educação especial, para os efeitos desta Lei, a modalidade de educação escolar oferecida preferencialmente na rede regular de ensino, para educandos com deficiência, transtornos globais do desenvolvimento e altas habilidades ou superdotação. $\S 1^{0} 15$ Haverá, quando necessário, serviços de apoio especializado, na escola 
DOI: $10.12957 /$ e-mosaicos.2020.46091

regular, para atender às peculiaridades da clientela de educação especial. § $2^{\circ} \mathrm{O}$ atendimento educacional será feito em classes, escolas ou serviços especializados, sempre que, em função das condições específicas dos alunos, não for possível a sua integração nas classes comuns de ensino regular. $\S 3^{\circ} \mathrm{A}$ oferta de educação especial, dever constitucional do Estado, tem início na faixa etária de zero a seis anos, durante a educação infantil (BRASIL, 1996).

Entretanto, não é apenas a legislação que assegurará que os alunos com necessidades educacionais especiais sejam tratados com respeito, mas sim a consciência de todos os envolvidos nos processos de ensino.

Nesse contexto, surgiram as questões e a proposta de intervenção deste trabalho que está sendo apresentado, com o propósito de despertar um novo olhar nos docentes. Sabemos que a legislação foi um grande avanço, mas para que se efetive a inclusão é necessário que as pessoas envolvidas no processo aceitem os desafios, acreditem que é possível. Desta forma, a educação inclusiva deixará de ser apenas garantida pela legislação e passará a ser realidade nas escolas brasileiras e na sociedade.

\section{IDENTIFICAÇÃO DA SITUAÇÃO PROBLEMA E METODOLOGIA}

Durante o curso de Especialização em "Educação Inclusiva em Contextos Escolares", tive a oportunidade de refletir muito sobre o processo de inclusão. Com isso, algumas inquietações foram surgindo e passei a observar com mais atenção a rotina da escola em que eu trabalho.

Analisei o trabalho docente e da equipe gestora em todos os seguimentos de ensino do colégio (Ensino Infantil, Fundamental I e II e Médio), sendo possível perceber a dificuldade de receber e incluir estudantes com necessidades educacionais especiais nas classes regulares. A escola tem alguns alunos com deficiências, que recebem atendimentos com especialistas fora do colégio por conta dos pais, mas durante as aulas eles não têm acompanhamento específico. Os professores que estão em sala com esses alunos apontam a necessidade de maior apoio ao processo de aprendizagem. Percebi também a resistência da coordenação e de professores em receber um aluno com deficiência em sala, por apresentarem medos e angústias.

Diante do exposto, foi oferecida uma oficina pedagógica de sensibilização, com duração de 03 (três) horas. Inicialmente foi feito uma acolhida, reflexão e discussão a partir de um texto e de um vídeo. Em seguida, uma breve apresentação em slides abordando aspectos referentes à inclusão escolar e o desenvolvimento de atividades de sensibilização: vendar os olhos e ouvir a música "Trem bala", de Ana Vilela, usar meias grossas para pegar objetos, pentear os cabelos, abotoar blusas e assistir um vídeo com janela em LIBRAS e pedir que interpretem o que assistiram. Ao final, foi pedido um relato por parte dos participantes sobre suas sensações, como se sentiram e se comportaram estando no lugar do outro, vivenciando seus limites, possibilidades 
DOI: $10.12957 / \mathrm{e}-\mathrm{mosaicos} .2020 .46091$

e diferenças. De modo a trazer o conceito de alteridade como uma vivência, para que os docentes pudessem refletir sobre o que é uma pessoa com deficiência. E como poderiam contribuir, de fato, para a inclusão desses alunos.

Optei pela elaboração de uma oficina de sensibilização para realizar junto aos docentes, ao constatar a dificuldade dos professores e gestores da escola em realmente incluírem os alunos com necessidades especiais à rotina e contribuir para seu desenvolvimento. Acredito na importância e na urgência da inclusão e na necessidade da aceitação e convivência com a diversidade para a construção de uma sociedade mais justa e pacífica.

Assim, a questão que motivou essa proposta de estudo é: como formar docentes para a pluralidade e singularidade presentes nas salas de aula?

\section{JUSTIFICATIVA}

As rápidas transformações que vêm ocorrendo na sociedade atual e, sobretudo, o processo de globalização que envolve as esferas econômicas, políticas e sociais tem provocado repercussões variadas em diversas áreas e aspectos da vida social, bem como nos múltiplos grupos sociais que integram as diferentes regiões do nosso país, surgindo, então, a necessidade de criação de mecanismos que garantam a construção de uma sociedade mais justa, mais equânime.

Essas mudanças implicam em uma busca por um modelo educativo que contemple os anseios de uma sociedade inclusiva, baseado em princípios e leis que reconheçam a necessidade de uma educação para todos, onde a preocupação com o respeito às diferenças é fundamental para a consolidação do paradigma inclusivo.

De acordo com Souza e Silva (2005), numa abordagem de atenção à diversidade e à inclusão social, a educação apresenta-se como um fator importante de transformação social, em que novas propostas estão sendo desenvolvidas em torno de um ensino que atenda a todos os estudantes e a suas diferentes necessidades educacionais.

A escola inclusiva valoriza a diversidade e a subjetividade que existe no ser humano, pretende acolher na sala comum de ensino alunos com todo o tipo de necessidade educacional especial, seja ela advinda de condições econômicas, orgânicas, ambientais ou psicológicas.

Segundo Aranha (2004):

No âmbito da educação, a opção política pela construção de um sistema educacional inclusivo vem coroar um movimento para assegurar a todos os cidadãos, inclusive aos com necessidades educacionais especiais, a possibilidade de aprender a administrar a convivência digna e respeitosa numa sociedade complexa e diversificada (p. 20). 
DOI: $10.12957 /$ e-mosaicos.2020.46091

A dificuldade em transformar o discurso sobre inclusão em uma prática generalizada e permanente tem sido atribuída a diversos aspectos (SKLIAR, 1997; BUENO, 2008; GLAT \& PLETSCH, 2011; KASSAR, 2012). Uma das principais barreiras, mesmo nos dias atuais, quando muito já se tem discutido sobre a questão, ainda é, sem dúvida alguma, o despreparo e/ou resistência dos profissionais da educação para atuarem em uma nova configuração educacional.

Diante disso, a ideia da oficina pedagógica para docentes teve como propósito incentivar e sensibilizar todos os docentes. $\mathrm{O}$ convite foi aberto aos professores de todos os segmentos que tivessem interesse, através de uma ficha de inscrição. Mas apenas um grupo de professores se inscreveu, pois, nem todos puderam participar da atividade devido à incompatibilidade de horários e outros compromissos. A oficina foi realizada como atividade prático-reflexiva, visando promover sensibilização e despertar um olhar diferenciado dos educadores para todos os alunos com necessidades educacionais especiais. Salientando a importância da inclusão nas instituições de ensino comum.

O documento "Referenciais para Formação de Professores" (MEC, 1999) estabelece que:

O professor precisa ter condições de se desenvolver profissionalmente para assumir com autonomia o comando de seu trabalho, pois só assim poderá oferecer as condições necessárias para o desenvolvimento de seus alunos, atendendo as suas diferenças culturais, sociais e individuais (p. 3).

Tomando como base essa concepção, o objetivo da formação de professores é a sua profissionalização por meio do desenvolvimento de competências de modo a permitir que no cumprimento de suas funções estejam contempladas as dimensões técnicas, sociais e políticas que são igualmente importantes e imprescindíveis ao desenvolvimento educacional brasileiro.

Ao analisarmos criticamente a situação atual da formação de professores no Brasil, torna-se claro a necessidade de que o movimento de renovação da educação esteja fundamentado na concepção de formação na perspectiva da educação inclusiva e que esta formação precisa se ancorar nas competências acima descritas de forma a contemplar as necessidades de uma prática pedagógica articulada com os valores de uma escola plural e igualitária.

Esta missão atribui às escolas novas funções a desempenhar, o que pode provocar tensões entre os diferentes protagonistas do processo educativo. A inclusão escolar tem como um de seus objetivos garantir o convívio entre crianças e adolescentes com e sem deficiências ou outras necessidades educacionais especiais. Por meio de uma educação inclusiva é possível construir uma sociedade também inclusiva. 
DOI: $10.12957 /$ e-mosaicos.2020.46091

Como, então, garantir o direito à aprendizagem para todos? Como ensinar a alunos tão diferentes dentro de uma mesma sala de aula? Como garantir que todos aprendam e se alfabetizem em tempo oportuno? O 'como fazer' é o grande desafio vivido pelos educadores. Com o objetivo de provocar nos professores uma reflexão sobre a inclusão e como é a sensação de estar no lugar do outro, passando pelas dificuldades do outro, surgiu a proposta de um momento de formação docente em serviço, por meio da aplicação de uma oficina de sensibilização.

\section{Objetivo geral}

Este projeto de intervenção teve como objetivo desenvolver uma oficina com a finalidade de incentivar e sensibilizar os professores sobre a importância da inclusão nas instituições de ensino comum.

\section{ObJetIVOS ESPECÍ́ficos}

- $\quad$ Discutir a importância da inclusão escolar e da formação docente.

- $\quad$ Analisar a formação docente num contexto inclusivo.

- $\quad$ Promover vivências que proporcionem maior sensibilização dos docentes.

- Refletir sobre a educação inclusiva através do texto "Deficiências" de Renata Villela (ANEXO A) e do vídeo "As cores das flores"3.

\section{A PROPOSTA DE INTERVENÇÃO}

A intervenção pedagógica ocorreu a partir do desenvolvimento de uma oficina de sensibilização para um grupo de professores de uma instituição de ensino particular de orientação religiosa, localizada na cidade de Itu, no Estado de São Paulo. No ano letivo de 2019, a escola conta com aproximadamente 48 professores e 664 alunos matriculados regularmente na Educação Básica, nas seguintes etapas: Educação Infantil, Ensino Fundamental e Ensino Médio.

Os educandos são de ambos os sexos e estão distribuídos em dois períodos: manhã - para o Ensino Fundamental do $6^{\circ}$ ao $9^{\circ}$ ano e Ensino Médio - da $1^{a}$ à $3^{a}$ série; e à tarde - para a Educação Infantil, nas classes de Maternal I e II, Pré I e II e Ensino Fundamental, do $1^{0}$ ao $5^{\circ}$ ano, totalizando 33 turmas na escola.

A escola possui prédio próprio, com 33 salas de aula estruturadas com equipamentos e móveis escolares; 01 Laboratório Multidisciplinar de Ciências; 01 Laboratório de Informática; 01 sala especial de Formação e Música; 01 sala especial

\footnotetext{
${ }^{3}$ Vídeo disponível em: <https://www.youtube.com/watch?v=s6NNOeiQpPM>, acesso realizado em fevereiro de 2019.
} 
DOI: $10.12957 /$ e-mosaicos.2020.46091

para Artes; 02 salas de material didático; 01 Biblioteca; 01 sala de Convivência; 02 Ginásios Poliesportivos cobertos; 02 quadras de esportes descobertas; 01 campo gramado; 02 parques infantis; 01 piscina semiolímpica; 01 auditório; 01 capela; 03 estacionamentos e grandes áreas ajardinadas.

Atualmente, o colégio tem recebido alguns alunos com deficiências. No segmento da Educação Infantil, mais especificamente no Maternal II, há um caso de Autismo; e no Fundamental I, há três casos: um no $1^{\circ}$ ano, um no $2^{\circ}$ ano e um no $3^{\circ}$ ano; nos dois casos do $2^{\circ}$ e $3^{\circ}$ ano os alunos são irmãos. O colégio tem também uma aluna no $2^{\circ}$ ano do Ensino Médio com deficiência intelectual e física (cadeirante). E o último, é um aluno do $3^{0}$ ano do Ensino Médio, que possui síndrome de Down. Totalizando seis alunos com deficiências. E um dos maiores desafios educacionais é criar um ambiente de inclusão e convívio entre todos os alunos no espaço escolar.

A seguir será descrita a aplicação da oficina de sensibilização, denominada "Alteridade: eu no lugar do outro", com duração de 03 (três) horas, para um grupo de 25 professores.

O primeiro momento, com duração de cerca de 30 minutos: acolhida, reflexão e discussão a partir do texto de Renata Villela "Deficiências" (ANEXO A) e do vídeo "As cores das flores".

Segundo momento, com duração de aproximadamente 30 minutos: apresentação em slides abordando aspectos referentes à inclusão escolar (ANEXO B).

Intervalo de 30 minutos.

Terceiro momento, com cerca de 1 hora e 30 minutos, desenvolvimento de atividades de sensibilização, listadas a seguir:

- vendar os olhos e ouvir a música "Trem bala", de Ana Vilela 4.

- usar meias grossas para pegar objetos, pentear os cabelos, abotoar blusas. assistiram.

- assistir um vídeo com janela em LIBRAS $^{5}$ e pedir que interpretem o que

Quarto e último momento, com duração aproximada de 30 minutos, relato por parte dos participantes sobre suas sensações, como se sentiram e se comportaram estando no lugar do outro, vivenciando seus limites, possibilidades e diferenças.

\section{RELATÓRIO dE DESENVOLVIMENTO dO PROJETO DE INTERVENÇÃO PEDAGÓGICA}

A intervenção pedagógica aconteceu no dia 04/04/2019 através de uma oficina pedagógica de sensibilização denominada "Alteridade: eu no lugar do outro".

A oficina ocorreu no próprio espaço do colégio, no horário de $17 \mathrm{~h} 30 \mathrm{~min}$, no auditório. O convite foi aberto aos professores de todos os segmentos que tivessem interesse, através de uma ficha de inscrição. Tivemos presente um grupo de 25

\footnotetext{
${ }^{4}$ Música disponível em: < https://www.kboing.com.br/ana-vilela/trem-bala/>, acesso em Fevereiro de 2019.

${ }^{5}$ Janela em Libras disponível em: <https://www.youtube.com/watch?v=FZruODJb8TU >, acesso em Fevereiro de 2019.
} 
DOI: $10.12957 /$ e-mosaicos.2020.46091

professores do total de 48 , pois nem todos puderam participar da atividade devido à incompatibilidade de horários e outros compromissos, conforme já explicitado anteriormente.

No primeiro momento, os docentes foram acolhidos e dispostos em cadeiras que formavam um círculo. Em seguida, houve uma pequena apresentação sobre a atividade proposta, na qual expus a importância de eles estarem ali, de me doarem um pouquinho do tempo deles, sendo que depois de um dia longo de trabalho ainda iriam ficar por aproximadamente 03 horas, mas que esse momento seria de muita reflexão e importância.

Dando continuidade à oficina, comecei a reflexão através do poema de Renata Villela "Deficiências" (ANEXO A), o texto discorre sobre como podemos ser deficientes perigosos para nós mesmos e para aqueles que nos cercam. $\mathrm{E}$ alerta que deficiências éticas e comportamentais são mais destruidoras dos que as deficiências físicas, já que essas são, na maioria das vezes, imperceptíveis a olho nu. 0 objetivo de iniciar com esse texto, foi justamente tocar os professores. Para que eles, antes de começarem a listar as dificuldades de trabalhar com alunos com necessidades educativas especiais, refletissem que é parte da tarefa docente proporcionar uma metodologia inclusiva que atenda às necessidades dos estudantes. Não se trata somente de um olhar sensibilizado, mas a questão do direito à educação que todos têm.

Utilizei também o vídeo "As cores das flores" que conta a história de um garoto, chamado Diego, que lida com o desafio de uma atividade escolar. Sem o recurso da visão, ele cria uma lógica particular para se relacionar com a realidade, que recebe significados para além das definições usuais. 0 mais interessante é que em nenhum momento é colocado em dúvida se o menino realizará a tarefa. A expectativa é de como irá realizá-la. Vale destacar que o vídeo mostra que, além desse apoio de pessoas próximas, a estrutura escolar e os profissionais envolvidos foram importantes para possibilitar esse contexto de sucesso na aprendizagem. Essa rede de confiança na capacidade de aprendizagem da criança se explicita em todas as situações. Isso é acreditar que toda criança pode aprender!

Logo de início percebi que o texto e o vídeo tinham alcançado o objetivo proposto, alguns comentários foram surgindo, os professores começaram a expor sobre o mundo corrido em que vivemos e que não damos a devida atenção para o outro, o quanto é mais fácil apontar as dificuldades do outro do que enxergar as potencialidades.

[...] eles precisam de trabalhos diferenciados, atenção. Tenho que fazer da melhor forma possível para que o meu aluno se sinta incluído no ambiente escolar. As atividades diferenciadas fazem toda diferença. Não posso ficar esperando pela escola. (Professor A).

A inclusão propicia a interação do aluno com outros alunos, o que é um ponto positivo. $\mathrm{O}$ apoio da escola e da família retratada no vídeo faz toda diferença. Nós precisamos acreditar mais nos nossos alunos. (Professor B) 
DOI: $10.12957 /$ e-mosaicos.2020.46091

Uma educação que proporcione inclusão social deve oferecer um ensino adequado às diferenças e particularidades de cada aluno. Uma educação inclusiva jamais deve ser vista de maneira isolada, mas como parte do sistema regular (SANT'ANA, 2005; GLAT \& FERNANDES, 2005).

É necessário que haja uma formação contínua e adequada para professores. Segundo Bueno (1999), "Dentro das atuais condições da educação brasileira, não há como incluir crianças com necessidades educativas especiais no ensino regular sem apoio especializado, que ofereça aos professores dessas classes, orientação e assistência".

No segundo momento, iniciei a apresentação teórica usando slides (ANEXO B) com alguns tópicos e informações que considero relevantes. Procurei abordar informações claras e objetivas para que não ficasse cansativo. Ressaltei a importância da inclusão, o que seria uma escola inclusiva, os fundamentos legais, como podemos construir uma escola inclusiva e para finalizar algumas reflexões.

O objetivo foi sensibilizar e estimular esses professores para que pudessem buscar uma formação adequada para atender essa nova demanda de alunos e fomentar espaços de reflexão crítica sobre o cotidiano escolar em uma perspectiva de formação diferenciada para os professores que vivenciam a questão da inclusão em seu fazer docente, que é algo importante e que deve sempre ser oportunizado.

Segundo Lima (2002, p.40), "a formação de professores é um aspecto que merece ênfase quando se aborda a inclusão. Muitos dos futuros professores sentemse inseguros e ansiosos diante da possibilidade de receber uma criança com necessidades especiais na sala de aula. Há uma queixa geral de estudantes de pedagogia, de licenciatura e dos professores com o discurso de que não fui preparado para lidar com crianças com deficiência".

Durante a oficina alguns professores puderam expor essas angústias, comentaram que as leis foram um grande avanço, mas que eles às vezes se sentem realmente despreparados para receber essa demanda por conta da formação, da estrutura escolar. Falaram que na faculdade não foram preparados para trabalhar com esse público, quase nada se foi falado no curso de graduação sobre deficiências.

Penso que a escola e professores não estão preparados para inclusão, principalmente as deficiências mentais. A faculdade só te dá uma base, um suporte. Eu diria uns $50 \%$ e os outros $50 \%$ é na prática, na vivência. (Professora C).

As leis foram um grande avanço, mas ainda tem muito a se fazer. (...) já trabalhei em escolas em que não apresentavam estrutura nenhuma nem física, nem suporte pedagógico. Eu já me deparei com momentos complicados em que pensei em desistir. Na faculdade pouco se foi falado, temos que buscar informações por conta própria. Hoje ainda temos a internet que ajuda bastante. (Professora D). 
DOI: $10.12957 /$ e-mosaicos.2020.46091

Já no terceiro momento, após um intervalo de 30 minutos para um café, demos continuidade com a parte prática da oficina. E que seria a parte mais importante do meu ponto de vista, pois seria um momento de sentir o que nossos alunos sentem, quando de fato não são incluídos na sala de aula. Expliquei que iríamos fazer três atividades para que nos colocássemos no lugar do outro. Iniciei com a atividade de pegar objetos, pentear os cabelos e abotoar blusas usando luvas e meias grossas nas mãos. Foi um momento de bastante apuro, pois os docentes sentiram muita dificuldade em executar as tarefas, mas foi um momento bem descontraído. Eles diziam que não estavam conseguindo fazer algo tão simples do dia a dia.

Em seguida, passamos para a outra atividade que foi assistir um vídeo em Libras. Utilizei a oração do "Pai Nosso" em Libras, pois sabia que era uma oração comum a todos e que independente da religião todos conheciam, ou alguma vez na vida já ouviram. Procurei um texto fácil em que a sinalização era feita bem devagar, para que eles tentassem entender, sem som e sem legenda, só com a sinalização em Libras, e em seguida explicassem o que foi dito, mais uma vez os docentes tentaram se concentrar para executar a tarefa.

Alguns professores, com bastante dificuldade, conseguiram identificar algumas palavras mais simples como "céu", "terra". Ao término, os docentes ficaram surpresos por não terem percebido que era uma oração tão comum, conhecida e que eles não a identificaram.

Levantamos a questão do Tradutor/Intérprete de Língua de Sinais (TILS) que tem um papel muito importante na comunicação entre ouvintes e surdos. Sem essa mediação a comunicação entre esses sujeitos fica interrompida, principalmente na sala de aula, onde o aluno surdo está inserido na sala regular de ensino com os demais colegas e professores ouvintes, que podem não possuir certo conhecimento nessa língua. Mas o professor, mesmo não sabendo Libras, pode ajudar seu aluno, ao falar devagar e de frente para o aluno, seria algo simples que muitos docentes não se atentam e $o$ aluno fica perdido.

A última atividade foi a de vendar os olhos ao som da música "Trem Bala", de Ana Vilela. Com o objetivo de mostrar a realidade de uma criança com deficiência visual, os docentes foram vendados. Eles ficaram com os olhos tampados, sentindo, vivenciando algumas atividades. Solicitei que fizessem atividades básicas como escrever uma frase, criar um desenho e tentar colori-lo; caminhar sozinho pelo ambiente. Em seguida, dividi o grupo em duas equipes: um com vendas e outro sem vendas, ou seja, "cegos" e "videntes".

A primeira equipe, "os videntes", sem olhos vendados seriam os guias dos outros professores que estavam vendados, "os cegos", numa atividade que envolvia movimentos corporais. Fui explicando que tipo de movimentos eles iriam executar fazendo referência ao que a música falava. Os guias iriam ajudar no giro, no balanço da música, para que ninguém caísse e percebessem que precisamos do outro, e queria que observassem que podemos aguçar outros sentidos, como a audição, para melhor nos situarmos. A ideia era eles construíssem uma coreografia sem ver a orientação, apenas ouvindo. Essa foi uma forma de sentirem, por alguns minutos, o que um aluno 
DOI: $10.12957 /$ e-mosaicos.2020.46091

cego sente. Puderam promover um aprendizado na prática de algo que apenas com discurso, teoria é bem mais difícil.

No quarto e último momento, com duração aproximada de 30 minutos, ocorreu o relato por parte dos participantes sobre suas sensações, como se sentiram e se comportaram estando no lugar do outro, vivenciando seus limites, possibilidades e diferenças.

Diante dos relatos dos docentes ficou perceptível que eles ficaram bastante emocionados. A professora $E$ relatou que:

Me senti bastante tocada com as atividades, pois tenho um aluno com autismo, e vejo a importância de estimulá-lo, mas é muito difícil conseguir dar atenção a ele o tempo todo, pois tem um planejamento a cumprir e tem outras crianças que precisam de minha ajuda também. (Professora E)

A inclusão é benéfica a todos, pois faz com que as crianças e os adultos tenham oportunidade de conhecer e conviver com a vida humana em todas as suas dimensões e desafios. E segundo Mantoan (2015):

A escola prepara o futuro e, de certo que, se as crianças aprenderem a valorizar e a conviver com as diferenças nas salas de aula, serão adultos bem diferentes de nós, que temos de nos empenhar tanto para entender e viver a experiência da inclusão! (p.91)

A professora $\mathrm{F}$ relatou que a oficina a fez refletir sobre como podemos contribuir para esse processo de inclusão, mas que é complicada essa posição do professor de chegar e ter um aluno com necessidade especial. Ele olha para o aluno e pensa: o que vou fazer?

Porque nós não temos nenhuma formação, nem nós que somos mais antigas, nem os novos. Então não sabemos como essa inclusão vai acontecer. Isso gera uma angústia e medo. (Professora F).

O professor G ressaltou a importância da formação inicial e continuada para os docentes. Ele afirma que:

O mundo mudou, portanto não temos os mesmos alunos de dez anos atrás, precisamos aceitar e buscar novos conhecimentos. E como educador precisamos nos adequar. Ninguém é igual. Todo tipo de preconceito, rótulos e estereótipos são prejudiciais às pessoas e relacionamentos. É preciso que aprendamos o respeito, a paciência e tolerância para que tenhamos relacionamentos mais saudáveis. (Professor G).

De acordo com Glat \& Blanco (2015): 
DOI: $10.12957 /$ e-mosaicos.2020.46091

Mais do que nova proposta educacional, a Educação Inclusiva pode ser considerada uma nova cultura escolar: uma concepção de escola que visa ao desenvolvimento de respostas educativas que atinjam a todos alunos (...). A proposta de Educação Inclusiva implica, portanto, um processo de reestruturação de todos os aspectos constitutivos da escola. (p.16-17).

A professora $\mathrm{H}$ relatou que esse tipo de encontro não existe na escola, não há professores de apoio, pouco se fala nesse assunto. Disse que procura informações por conta própria quando chega um aluno na sala é que vai ver o que dá para fazer.

[...] a escola ainda não tem suporte necessário para trabalhar de forma eficiente, creio que me falta capacitação para desenvolver atividades com esses alunos. Fica evidente que a simples inserção de alunos com necessidades educativas especiais, sem nenhum tipo de apoio ou assistência aos sistemas regulares de ensino não dá certo. (Professora H).

O professor I também salientou a importância de se falar mais sobre o assunto:

Precisamos falar mais sobre a inclusão, ter rodas de conversas para que possamos expor sobre nossas experiências, medos e frustações. Ouvir a opinião de professores que passaram ou passam por isso. Ressaltar a evolução dos nossos alunos, ver se estamos no caminho certo. Sem esse feedbacknão sabemos se evoluímos ou retrocedemos. (Professor I)

Mantoan (2015) nos propõe:

Se o que pretendemos é que a escola seja inclusiva, é urgente que seus planos se redefinam para uma educação voltada para a cidadania global, plena, livre de preconceitos e que reconhece e valoriza as diferenças.

Compreendemos que esta experiência despertou um novo olhar aos docentes, eles puderam refletir sobre a importância da inclusão nas instituições de ensino regular e vivenciar situações reais que perpassam suas salas de aula. Ao final da experiência todos os participantes puderam analisar o processo de formação e fazer suas contribuições sobre a experiência. Acredita-se que mais espaços de diálogo e debate são fundamentais para a formação de professores. Com a oficina, ficou perceptível também a necessidade de formação docente continuada e de um trabalho a ser realizado em conjunto. Os professores em geral puderam se colocar no lugar do outro e que este pode ser o início de um processo de formação para práticas inclusivas. 
DOI: $10.12957 /$ e-mosaicos.2020.46091

\section{CONSIDERAÇões FINAIS}

Este projeto de intervenção teve como objetivo desenvolver uma oficina com a finalidade de incentivar e sensibilizar os professores sobre a importância da inclusão nas instituições de ensino comum, considerando que dentro da realidade da escola que foi o local da aplicação essa estratégia não é utilizada com frequência.

A oficina teve os objetivos alcançados, apesar de que nem todos os professores tiveram a oportunidade de participar, mas ainda assim tivemos um número significativo e um bom envolvimento de quem esteve presente, o que pode nos sugerir que o grupo participante pode funcionar como multiplicador da experiência vivenciada na oficina, ao iniciar novas discussões e reflexões junto aos colegas de trabalho.

Podemos perceber que os profissionais, apesar de alguns buscarem informações e qualificações para desenvolver práticas pedagógicas diferenciadas, coerentes com os processos de inclusão, queixam-se de não encontrar espaços de reflexão coletiva para lidar com os desafios cotidianos.

Diante disso, se apresenta um duplo desafio: o primeiro é o de planejar pautas temáticas que promovam estudos aprofundados e qualificados que respaldem reflexões entre os participantes. O segundo desafio é o de possibilitar que nestes espaços se garanta um debate em que os mesmos possam expor suas ideias, dúvidas, conhecimentos e angústias.

O entendimento sobre a percepção e a vivência dos professores em relação aos alunos com necessidades educacionais especiais, a análise de preconceitos existentes e a conscientização sobre o papel docente nos processos de inclusão são fatores importantes e determinantes para o desenvolvimento educacional pleno de todos os estudantes.

Compreendemos que esta experiência despertou a inquietação do grupo de professores e um novo olhar sobre as temáticas selecionadas. Entretanto, entendemos também que não se tratou de um rompimento definitivo com algumas mentalidades que se distanciam de princípios inclusivos. A oficina pode ser compreendida como geradora de reflexões e de incômodos que podem despertar interesse e busca por novas perspectivas para um novo pensar e agir na docência.

\section{REFERÊNCIAS}

ANTUNES, K. C. V. \& GLAT, R. Formação de professores na perspectiva da educação inclusiva: os Cursos de Pedagogia em foco. In: PLETSCH, M. D. \& DAMASCENO, A. (Org.). Educação especial e inclusão escolar: reflexões sobre o fazer pedagógico. Seropédica, RJ: EDUR/UFRRJ, 2011.

ARANHA, M. S. F. Projeto Escola Viva. Alunos com necessidades educacionais especiais. Visão Histórica, v.1 In: Brasília: MEC, SEESP, 2004, 7-39. 
DOI: $10.12957 /$ e-mosaicos.2020.46091

BRASIL. Lei $n^{\circ}$ 9.394, de 20 de setembro de 1996. Estabelece as diretrizes e bases da educação nacional.

. Ministério da Educação. Secretaria de Educação Especial. Parecer 017/2001. Brasília: MEC/SEESP, 2001.

. Referenciais para a Formação de Professores. MEC, 1999.

RESOLUÇÃO CNE/CEB No 2, DE 11 DE SETEMBRO DE 2001. Institui Diretrizes Nacionais para a Educação Especial na Educação Básica.

BUENO, José Geraldo Silveira. As políticas de inclusão escolar: uma prerrogativa da educação especial? In: BUENO, José Geraldo Silveira; MENDES, Geovana Mendonça Lunardi; SANTOS, Roseli Albino (Orgs.). Deficiência e escolarização: novas perspectivas de análise. Araraquara, SP: Junqueira \& Marin; Brasília, DF: CAPES, 2008.

. Educação especial brasileira: integração /segregação do aluno diferente. São Paulo, EDUC/PUCSP, 1999.

GLAT R, FERNANDES EF. Da Educação Segregada à Educação Inclusiva: uma Breve Reflexão sobre os Paradigmas Educacionais no Contexto da Educação Especial Brasileira. Revista Inclusão: MEC/SEESP. 2005; 1(1).

GLAT, R. PLETSCH, M. D. Inclusão escolar de alunos com necessidades especiais. Rio de Janeiro: EDUERJ, 2011.

GLAT, R., \& BLANCO, L. de M. V. (2015). Educação Especial no contexto de uma Educação Inclusiva. In R. Glat (Org.), Educação Inc/usiva: Cultura e cotidiano escolar (2a ed., pp. 15-3). Rio de Janeiro: Sette Letras.

KASSAR, Mônica de Carvalho Magalhães. Política de educação especial na perspectiva inclusiva e o atendimento educacional especializado. In: MARTINS, Lúcia de Araújo Ramos; PIRES, Gláucia Nascimento da Luz; PIRES, José (Orgs). Inclusão escolar e social: novos contextos, novos aportes. Natal, RN: EDUFRN, 2012.

LIMA P.A. Educação inclusiva e igualdade social. São Paulo; AVERCAMP, 2002. MANTOAN, M. T. E. Inclusão escolar. o que é? Por quê? Como fazer? São Paulo: Summus, 2015.

PLETSCH, M. D. A formação de professores para a educação inclusiva: legislação, diretrizes políticas e resultados de pesquisa. Educar em Revista, n033. Curitiba, 2009. 
DOI: $10.12957 /$ e-mosaicos.2020.46091

SKLIAR, Carlos. Abordagens sócio antropológicas em Educação Especial. In: SKLIAR, Carlos (Org.). Educação e exclusão: abordagens sócio antropológicas em Educação Especial. Porto Alegre: Mediação, 1997.

SOUZA, Rita de Cácia Santos; SILVA, Greice Fabiane Santos. Inclusão na diversidade: um desafio para os educadores. In: Revista da Faced: UFBA, 2005.p.239 - 251 n009.

\section{Anexo a - Poesia de Renata Villela}

\section{Deficiências}

"Deficiente" é aquele que não consegue modificar sua vida, aceitando as imposições de outras pessoas ou da sociedade em que vive, sem ter consciência de que é dono do seu destino.

"Louco" é quem não procura ser feliz com o que possui.

"Cego" é aquele que não vê seu próximo morrer de frio, de fome, de miséria, e só tem olhos para seus míseros problemas e pequenas dores.

"Surdo" é aquele que não tem tempo de ouvir um desabafo de um amigo, ou o apelo de um irmão. Pois está sempre apressado para o trabalho e quer garantir seus tostões no fim do mês.

"Mudo" é aquele que não consegue falar o que sente e se esconde por trás da máscara da hipocrisia.

"Paralítico" é quem não consegue andar na direção daqueles que precisam de sua ajuda.

"Diabético" é quem não consegue ser doce.

"Anão" é quem não sabe deixar o amor crescer.

E, finalmente, a pior das deficiências é ser miserável, pois:

"Miseráveis" são todos que não conseguem falar com Deus.

"A amizade é um amor que nunca morre."

Fonte: Poema disponível em: <https://www.pensador.com/poema deficiencia/>, acesso em Março de 2019. 
DOI: $10.12957 / \mathrm{e}-\mathrm{mosaicos} .2020 .46091$

\section{ANEXO B - MINIATURA DOS SLIDESUSADOS NA APRESENTAÇÃO TEÓRICA.}

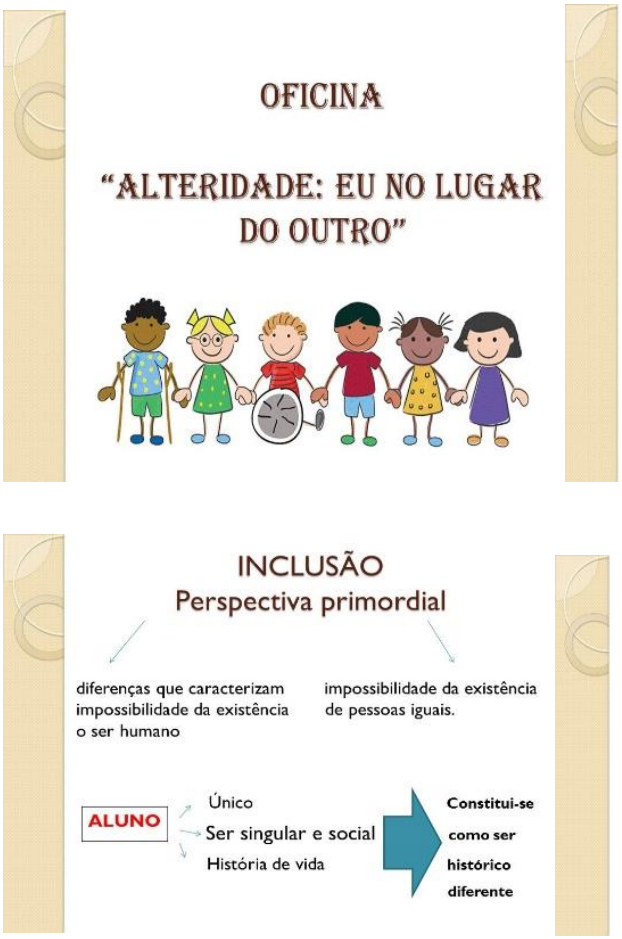

EDUCAÇÃ O INCLUSIVA: UM DESAFIO CONTEMPORÂNEO

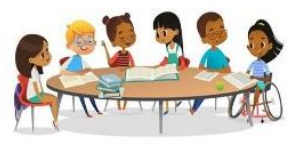

INCLUSÃO

RESPEITO AS SINGULARIDADES

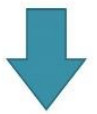

> Não se dá por Decreto.

Não é uma tentativa de igualizar todos e sim respeitar necessidades $\mathrm{e}$ particularidades.
Qual nossa concepção de DEFICÊNCIA?

Qual nossa concepção de INCLUSÃO?
- Inclusão, não significa simplesmente matricular Todos os educandos com Necessidades Educacionais Especiais na classe comum, ignorando suas necessidades específicas, mas significa dar ao professor e à escola $\circ$ suporte necessário a sua ação pedagógica.

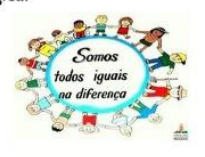

- Implica, construir um espaço democrático e competente para trabalhar com todos

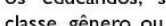
classe, gênero ou caracteristicas pessoais, baseando-se no principio de que diversidade deve não só ser aceita como desejada. (Diretrizes Nacionais para a Educaçăo Especial na Educaçăo Básica, 2001: p.40

\section{CONSTRUIR UMA ESCOLA} INCLUSIVA

- É um caminho que cada um deve traçar, experimentando, construindo suas próprias iniciativas e seu próprio percurso, de acordo com as necessidades, anseios, desejos de seus alunos e profissionais, considerando, os recursos e potencialidades de sua comunidade, ou seja, sua realidade escolar!

\section{QUESTÕES PARA REFLETIR}

- De acordo com Rosa Blanco, "não podemos esperar que todas as condições existam para começar a inclusão, porque senão nunca começaremos.(...) a inclusão é um processo gradativo, que leva tempo, que é complexo, que tem que ser construído aos poucos. Assim, as condições fazem parte do próprio processo".
- O que eu, enquanto professor, posso fazer para o meu aluno? 
DOI: $10.12957 /$ e-mosaicos.2020.46091

Somos todos deficientes e especiais

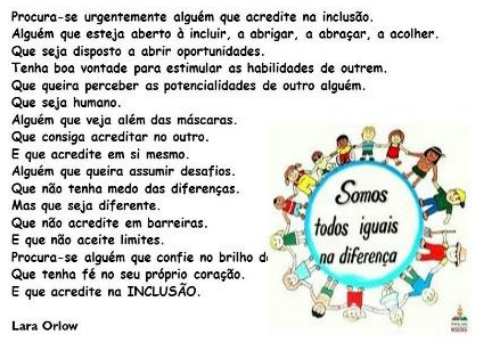

A Inclusão acontece quando...

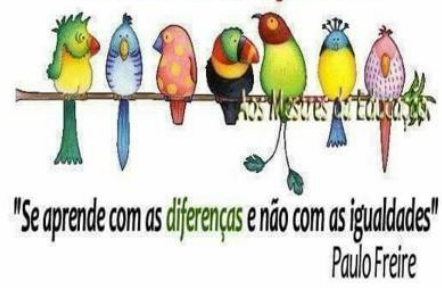

Recebido em 01 de julho de 2019

Aceito em 18 de outubro de 2019

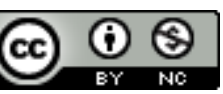

A e-Mosaicos Revista Multidisciplinar de Ensino, Pesquisa, Extensão e Cultura do Instituto de Aplicação Fernando Rodrigues da Silveira (CAp-UERJ) está licenciada com uma Licença Creative Commons - Atribuição-NãoComercial 4.0 Internacional.

Os direitos autorais de todos os trabalhos publicados na revista pertencem ao(s) seu(s) autor(es) e coautor(es), com o direito de primeira publicação cedido à e-Mosaicos.

Os artigos publicados são de acesso público, de uso gratuito, com atribuição de autoria obrigatória, para aplicações de finalidade educacional e não-comercial, de acordo com o modelo de licenciamento Creative Commons adotado pela revista. 